\title{
Wirtschaftsinformatik - Evolution of the Discipline as Reflected by Its Journal
}

\author{
In the course of 50 years, the journal "elektronische datenverarbeitung" (electronic \\ data processing) has changed to become "WIRTSCHAFTSINFORMATIK" (business and \\ information systems engineering), with the intermediate step of "Angewandte Informatik" \\ (applied computer science). The journal reflects major trends and changing topics of the \\ scientific discipline. The recent introduction of the triple strategy with three versions of \\ the journal aims at serving both research and business practice as well as establishing an \\ international forum for the research approaches of the German speaking countries.
}

DOI 10.1007/s12599-008-0022-3

\section{The Authors}

Prof. Dr. Ulrich Hasenkamp

Institut für Wirtschaftsinformatik

Philipps-Universität Marburg

Universitätsstr. 24

35032 Marburg

Germany

hasenkamp@wiwi.uni-marburg.de

Prof. Dr. Peter Stahlknecht

Institut für Informationsmanagement und Unternehmensführung

Universität Osnabrück

49069 Osnabrück

Germany

p.stahlknecht@oec.uni-osnabrueck.de

Received: 2008-08-04

Accepted: 2008-09-16

Accepted after two revisions

by Prof. Dr. Buhl

This article is also available in German in print and via http://www. wirtschaftsinformatik.de: Hasenkamp U, Stahlknecht P (2008) Das Fach Wirtschaftsinformatik im Spiegel seiner Zeitschrift. WIRTSCHAFTSINFORMATIK. doi: 10.1007/11576-008-0128-8.

\section{Introduction}

Initiated by the mathematician Hans Konrad Schuff (1927-1968) and supported by the local chamber of industry and commerce, the first European software house, named "Mathematische Beratungs- und
Programmierungsdienst GmbH (mbp)" was founded in Dortmund by 14 regional corporations on Feb. 26, 1957. Schuff was appointed executive manager.

In the same year Schuff, together with the publishing house Friedr. Vieweg \& Sohn, developed plans for a new journal under the title "electronic data processing" (ed) and the subtitle "technical reports on program controlled machines and their application". The first issue appeared in 1959. Fig. 1 shows an excerpt from the foreword by Alwin Walther, a famous data processing pioneer from the Technical University of Darmstadt.

According to the preface to the first edition, Schuff intended to include the following topics in the journal:

1. general reports on the situation regarding computing machinery and their application, etc.;

2. theoretical and practical reports on corporate automation, distinguishing

a) administrative automation in the management domain,

b) automation in engineering,

c) automation in production,

d) integration of corporate automation;

3. description of electronic computers new on the market;

4. programming practice;

5. short notices and discussion statements;

6. literature surveys, reviews, notes on relevant publications.

Already in this early stage, several topics were covered that are associated with the current understanding of BISE, especially regarding item 2 and others.
The founding of mbp as well as the publication of the journal mark the beginning of a revolutionary development that Schuff anticipated early by his visionary capabilities. One has to remember that to this time hardly anybody, in all parts of society, knew about the nature of programming and the profession of a programmer. Even less knowledge existed regarding the potential applications of the new medium electronic data processing (often called "electric" data processing). Up to the 1960 s some institutes of professional education marketed courses under the promising name "Introduction to programming" that were merely instructions for setting switches on tabulating machines. A paper of the journal "Der Betrieb" cited in issue 2/1960 of ed, titled "Is the application of electronic computing machinery a potential threat to the German economy", is typical of the widespread opinion in those days.

The development of the journal and the development of mbp are closely connected, at least until Hans Konrad Schuff died young on Feb. 14, 1968.

The journal ran under the original name "elektronische datenverarbeitung" until 1970, from 1971 until 1989 under the name "Angewandte Informatik", and from 1990 under the current name "WIRTSCHAFTSINFORMATIK". From the beginning in 1959 until 2008, it was published by the publishing house Vieweg. From volume 51 (2009) on, it is with the Gabler publishers (subsidiary of Springer Science+Business Media), who specialize in management and administration. 


\section{One of the most important German Blue Chips is yellow.}

The new Commerzbank. Your leading bank in Germany.

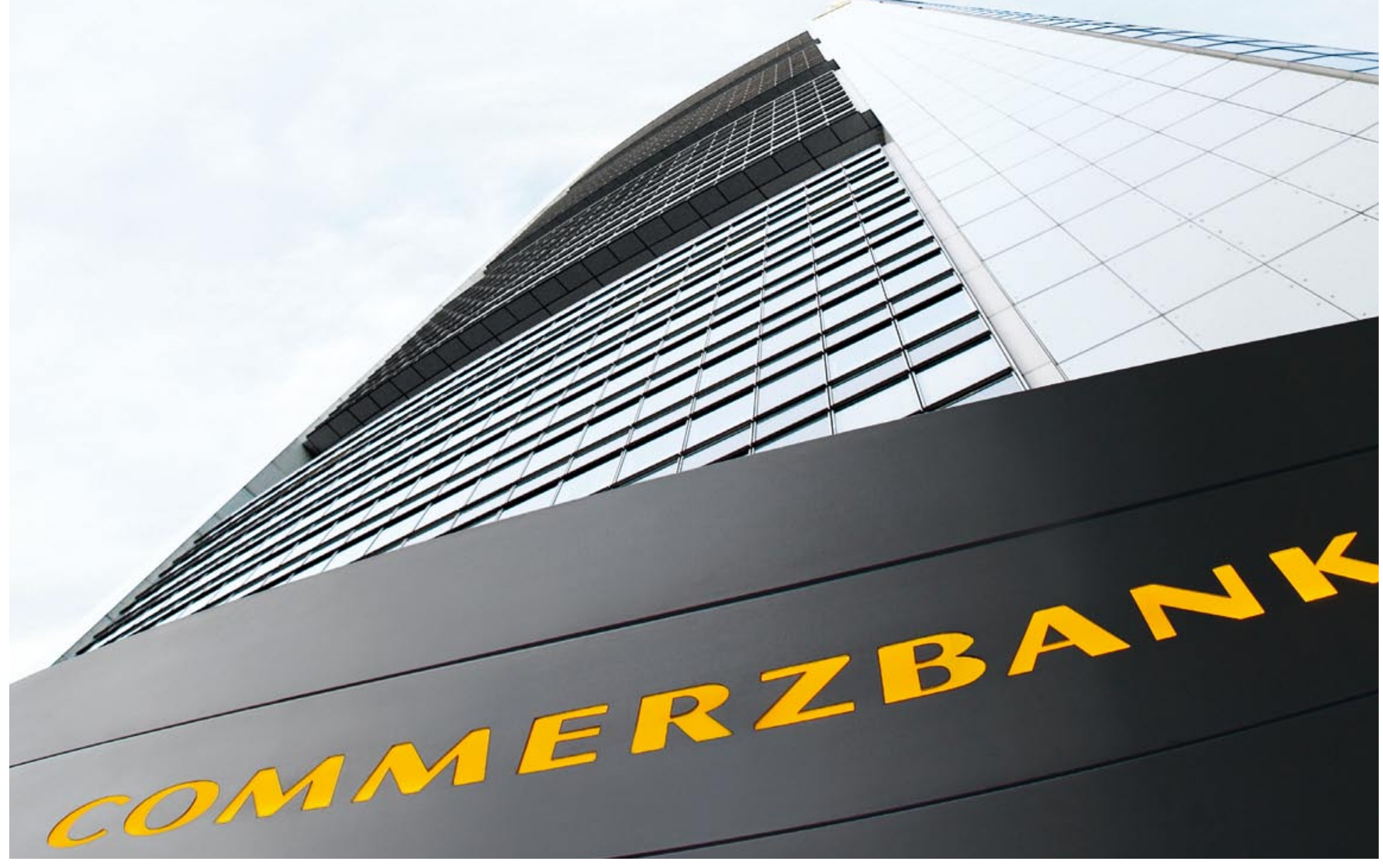

Following its takeover of Dresdner Bank, the new Commerzbank will become the leading bank for private and corporate banking in Germany. Its closely-knit network of roughly 1,200 branches available to customers exceeds that of all German banks. In addition our customers stand to benefit from an even wider and more powerful range of products and services.

The new Commerzbank promises to be an even stronger long-term partner for our corporate customers and especially for the SME, highly performing in the export sector. Already today, Commerzbank, the leading bank for foreign trade financing in the world's largest export economy accompanies its customers not only in Germany, but also across the globe. www.commerzbank.com 
Regarding electronic computing machinery and electronic data processing, in Germany the early pioneering work of Konrad Zuse is recognized, but later the development became slow and dilatory. There was a danger for the country of dropping out of the great and fast development process of a field which is equally important for science, industry, and the economy. Fortunately, this has changed nowadays. An indicator for the prosperity of a domain is the emergence of a specific journal. The journal on hand, "electronic data processing", based on technical reports, is such a journal.

Fig. 1 Excerpt from the foreword by Alwin Walthers, dated Jan. 9, 1959

The following sections inform about details, especially regarding the journal's content in the three differently named stages and regarding the genesis of BISE as understood today.

\section{2 elektronische datenverarbeitung}

\subsection{Organization and structure}

Hans Konrad Schuff was the journal's sole managing and technical editor from 1959 until he died in 1968. An obituary was printed in issue 3/1968. About 10 distinguished persons from business and science were listed as "contributors", transformed into an advisory board in 1967. Also in 1967 Wolf Eicken, an mbp employee, was appointed editorial staff.

The journal's appearance and content were determined almost exclusively by Schuff himself. He structured the content, based on the outline given in the preface to issue $1 / 1959$, into the sections A) scientific papers, B) conference reports, news, C) book reviews, summaries of articles from other sources, D) reports on computing systems, and E) general news. Section A sometimes also contained detailed reports on conferences and computing systems. Sections B) through E) were supplied in part by mbp employees whose names were in general not given at all, or sometimes only as initials. Schuff encouraged his staff to report on successful projects and effective software implementations.

In 1969, another mathematician, Paul Schmitz (1925-2005), succeeded Schuff as editor-in-chief. Schmitz worked for the hardware manufacturer UNIVAC Remington Rand and for mbp before he became manager of the computing center at the University of Cologne in 1970. In
1971, he was appointed professor on one of the first chairs for BISE in Germany at the University of Cologne.

In 1959 and 1960, the journal comprised four issues annually, from 1961 through 1966 six, 1967 and 1968 nine, and finally 1969 and 1970 twelve per year. Schuff's unorthodox and future-oriented attitude is visible also in details like intentional typographic abnormalities, special wording, and eye-catching color design. The visual appearance of the journal was - except for minor changes in fonts and cover graphics - not changed over all the 31 volumes from 1959 until 1989.

\subsection{Scientific articles}

Each of the 86 issues of ed that appeared between 1959 and 1970 comprises six to seven scientific articles. Papers in English make up for $8.5 \%$, with an increase towards the end of the reported period. Schuff himself authored 22 articles, the last one published in issue 6/1967.

According to one of the journal's intentions, many articles - especially in the early issues - report on electronic computing systems and trade shows. From today's perspective it is noteworthy that on the Hannover Industrial Fair in 1959 (CeBIT did not yet exist to that time) only 16 computing systems were on display. Many more appeared in the course of time that met increasing demand. Except for Bull, IBM, and Siemens, all manufacturers of that era (e. g. Ferranti, Telefunken, UNIVAC, Zuse) have vanished from the marketplace.

The application reports published in ed can best be outlined according to the internal structure of mbp. The company was organized into an administrative division, whose responsibilities included IT consulting and running a computing service center, and a technical/mathematical division with departments for mathematics/physics, structural engineering, and operations research. Special attention was brought to publications on methods of operations research that became known in Germany at the end of the 1950s. In ed, 68 papers on OR methods and applications were printed, many of them bearing at least indirect relations to BISE.

65 , i. e. $11.5 \%$, of the papers bear a clear relation to BISE. To summarize:

- The first application reports cover the industries banks/savings associations, insurance, breweries, and food chain stores.

- In terms of functions, the reported applications cover warehousing, material management, production scheduling and control, and market research.

- Applications in small and medium sized enterprises are restricted to the use of billing machines with punch tape devices because electronic computing systems were out of range for cost reasons.

- Articles with generalizable content are rarely found, which is in part due to the journal's intention to focus on applications. However, in issue 1/1959 two articles can be found that are still valid today to a large extent:

- a paper by the well-known American consultant John Diebold, titled "Electronic Computers - The Challenge to Management" and

- a paper by Karl-Heinz Kettner, Duisburg, on "The integrative effect of electronic data processing" 2 with the statement (to be judged under the prevailing circumstances) that "smaller and scientific computers are totally unsuitable for these tasks". In the report "IBM 1401 - a market success" by the same author in issue 2/1960 one finds the statement "For an integrated data processing in the sense of a modern organizational structure the capacity of the system is in no way sufficient". Kettner was by order of Thyssen AG evaluating the potential for corporate applications of the new medium data processing. Similar studies were conducted in almost every large company to that time.

- Special attention should be given to the fact that the catchword "standard soft-

\footnotetext{
The article is reprinted in this issue.

The article is reprinted in this issue.
} 
ware" (under another name) is mentioned in ed already, namely

- by describing a standard payroll program in issue 4/1964 and

- in a paper on the importance of problem oriented software for the design of corporate application systems in issue $1 / 1969$.

- The topic "management information systems" that had come up in the 1960s was covered relatively late in issue $7 / 1968$.

- Questions on systematic approaches to systems development, e. g. for assessing the present state or for the structuring of master data and transaction data, are first dealt with in 1968.

- Due to the never ending progress in information technology some topics are repeated over and over with different solutions, also in the field of BISE. This is true for e. $\mathrm{g}$.

- data collection and input, especially analyzed economically, which is dealt with in a series of ed articles,

- the question of IT distribution, centralization vs. decentralization. As early as in issue 3/1959 in a report on the annual meeting of the Society for Applied Mathematics and Mechanics we find a statement by Klaus Samelson (one of the inventors of the stack principle in programming) on a general tendency towards decentralization. The editorial staff of ed (presumably Schuff himself) had added the following footnote: "In contrast we notice that the multicorporate enterprises, which are currently emerging in Germany with a high level of centralization, tend to centralize data processing as well."

- Finally the question remains if in any ed article the word "Wirtschaftsinformatik" (BISE) has been used. The answer is yes, in an article by Erwin Grochla (1921-1986), the founder of BIFOA, a management oriented institute for organization and automation at the University of Cologne. The title of the article ${ }^{3}$ contains the word Wirtschaftsinformatik and postulates that BISE is a necessary application oriented complement to general computer science. The paper also suggests how to improve the academic education in the

\footnotetext{
3 The article, also known as the "Second BIFOA Memorandum", is reprinted in this issue.
}

\begin{tabular}{|lll|}
\hline Tab. 1 & Supplemental issues of the journal "elektronische datenverarbeitung" \\
\hline Suppl. & Subject & Author \\
\hline 1 & Theodor Fromme (The Equivalence Calculus - The Switching Matrices) & n. a. \\
\hline 2 & ALGOL 60 & n. a. \\
\hline 3 & Introduction to Information Theory & Henze $E$ \\
\hline 4 & The Punch Tape in Information Processing Systems & mbp (ed.) \\
\hline 5 & $\begin{array}{l}\text { Associative Storage } \\
\text { Operations Research - A Guide for Practitioners. } \\
6\end{array}$ & $\begin{array}{l}\text { Input-Output-Models, Optimization Methods } \\
\text { Operations Research - A Guide for Practitioners. }\end{array}$ \\
\hline 7 & $\begin{array}{l}\text { Simulation Methods, Sequencing and Scheduling } \\
\text { Learning Computers }\end{array}$ & Stahlknecht $P$ \\
\hline 8 & \begin{tabular}{l} 
Stahlknecht P \\
\hline
\end{tabular} & WolfF, Schmitt A \\
\hline
\end{tabular}

\begin{tabular}{|c|c|}
\hline Section & $\begin{array}{l}\text { Responsible members of the editorial board } \\
\text { (in chronological order) }\end{array}$ \\
\hline News from academia & Mertens, König, Hofmann, Rump \\
\hline Book reviews & Schmitz, Seibt, Heinrich, Uhr, Grauer, Oberweis \\
\hline Technical reports (gray literature) & Schmitz, Griese, Ehrenberg \\
\hline Dissertations & Roithmayr, Buxmann, Loos \\
\hline $\begin{array}{l}\text { Reports on interesting } \\
\text { articles in other journals }\end{array}$ & Mertens, Müller \\
\hline Reports on online resources & Knolmayer, Becker \\
\hline Innovative Product & Mertens, Winand, Spann \\
\hline Short notices & Hasenkamp \\
\hline Discussion & König, Buhl, Winter \\
\hline News of WKWI & The respective speakers \\
\hline News of Gl & The respective speakers \\
\hline Journal website & Hasenkamp, Rautenstrauch, Loos, Schoder \\
\hline Profile / Interview & Strunz, Mertens, Heinzl \\
\hline Catchword & Stahlknecht, Sinz \\
\hline State of the Art & $\begin{array}{l}\text { Mertens, Hansen, Stahlknecht, Krallmann, } \\
\text { Kurbel, Chamoni, Buxmann }\end{array}$ \\
\hline Student forum & Thome, Schumann, Weinhardt, Eymann \\
\hline Calendar & Hasenkamp \\
\hline Comparative literature study & Uhr, Frank \\
\hline
\end{tabular}

field of "automated data processing" in the Federal Republic of Germany.

In the years 1962 through 1966, supplemental issues of the journal ed have been published. According to the ideas of Schuff and the publishing house Vieweg, they were meant "to cover a certain domain or a specific problem in more detail". The topics of these supplements are listed in Tab. 1

\section{Angewandte Informatik}

\subsection{Organization and structure}

From 1971 on, the journal appeared under the title "Angewandte Informatik" (AI) with the subtitle "applied informatics", a literal translation of the German title. The reason for the name change is given in the foreword of issue 1/1971, a portion of which is depicted in Fig. 2. Paul Schmitz continued to be sole editor at first. In 1974 he was joined by Norbert Szyperski, to that time professor of general management and corporate planning at the University of Cologne and director of BIFOA. They continuously stayed sole managing editors until the last issue of AI in 1989. This includes the years in which Szyperski had left his university position to become CEO of the "Gesellschaft für Mathematik und Datenverarbeitung (GMD)" and later CEO of an industrial corporation. 
The new title shall express clearly what had already occurred in the editorial program of the former "elektronische datenverarbeitung" for a longer period: Opening, broadening, deepening, and intensifying the topic domain that "Angewandte Informatik" covers. Not only "program controlled machinery and their application" are the domain of this journal. Moreover: their economical, technical, social impact, their foundations, prerequisites, crosslinks, perspectives. In short: the editorial program of "Angewandte Informatik" covers the domain in a more comprehensive context.

Fig. 2 Excerpt from the foreword to the first issue of Al (issue 1/1971)

Originally, all the topics of applied computer science have been addressed in this journal. Today, this is not possible any more. Some areas, like e. g. medical informatics, that now have dedicated publication channels, have decreased substantially. In contrast, applications in the areas of business and administration have become a main focus. Furthermore, since the academic discipline "business and information systems engineering", which has expanded enormously during the last few years, does not have a specific journal yet, it is obvious that "Angewandte Informatik" steps forward and concentrates on business and information systems engineering. Therefore, this journal will be called "Wirtschaftsinformatik", starting with the next issue.

Fig. 3 Excerpt from the foreword to the last issue of Al (issue 11-12/1989)

As before, the editors were assisted by a scientific board (around 12 persons) and from 1975 on also by an editorial board (around 10 persons). At the occasion of the 25 th anniversary in 1984 , the two boards were unified to become an editorial board with about 15 members. In the same year, Ulrich Hasenkamp, to that time research assistant to Paul Schmitz, succeeded Wolf Eicken as head of the editorial staff.

AI had 12 issues per annum, with the exception of a few double issues. The structure comprising the sections A) scientific articles, B) conference reports, short notices and standardization work, and $\mathrm{C}$ ) book reviews was valid for the total span of 19 volumes. The last issue under the name of "Angewandte Informatik" was the double issue $11-12 / 1989$. The main rationale for changing the name to WIRTSCHAFTSINFORMATIK is stated in the foreword of this issue. An excerpt is given in Fig. 3.

\subsection{Scientific articles}

Within the 19 volumes of the journal "Angewandte Informatik" there had aver- by Cork that were included throughout the 1980s in order to loosen the content.

During the whole period from 1971 to 1989 , about $23 \%$ of the articles can be attributed to BISE, with the portion rising from $10 \%$ in the years 1971 through 1974 to almost $40 \%$ in the years 1986 through 1989. The articles counted in this sense include those that are devoted to exclusive topics of BISE (like accounting applications, HR information systems, merchandise information systems) and those that are also relevant to other fields of application of computer science (such as database design, prototyping, computer viruses).

The genesis of the scientific discipline can best be discovered by analyzing chronologically the first coverage of all the topics that are followed up in later issues. Based on this idea the following focal topics can be identified, like in a ledger: In 1971

a) a process model for deriving company-specific models of integrated data processing,

b) control of corporate information systems,

c) EDP-systems as subject matter of a contract.

Topic a) triggered several articles around the "Cologne integration model" by Grochla, topic b) induced numerous articles on management or executive information systems, and topic c) led to papers on hardware and software contracts in general and on the special conditions for buying and renting hardware and software by public administration.

In 1972

a) a proposal for the curriculum "Master in business administration specializing in computer science",

b) experiences with computer aided planning models.

Topic a) was mostly followed every year afterwards by articles containing suggestions and experiences regarding curriculum design in BISE, topic b) by articles on computer aided planning for companies or their divisions, partly based on OR models.

In 1974

a) system engineering with the goal of standardized systems analysis,

b) the impact of conflicts on project management.

Topic a) initiated numerous articles on systems development procedures, topic b) papers on project management. 


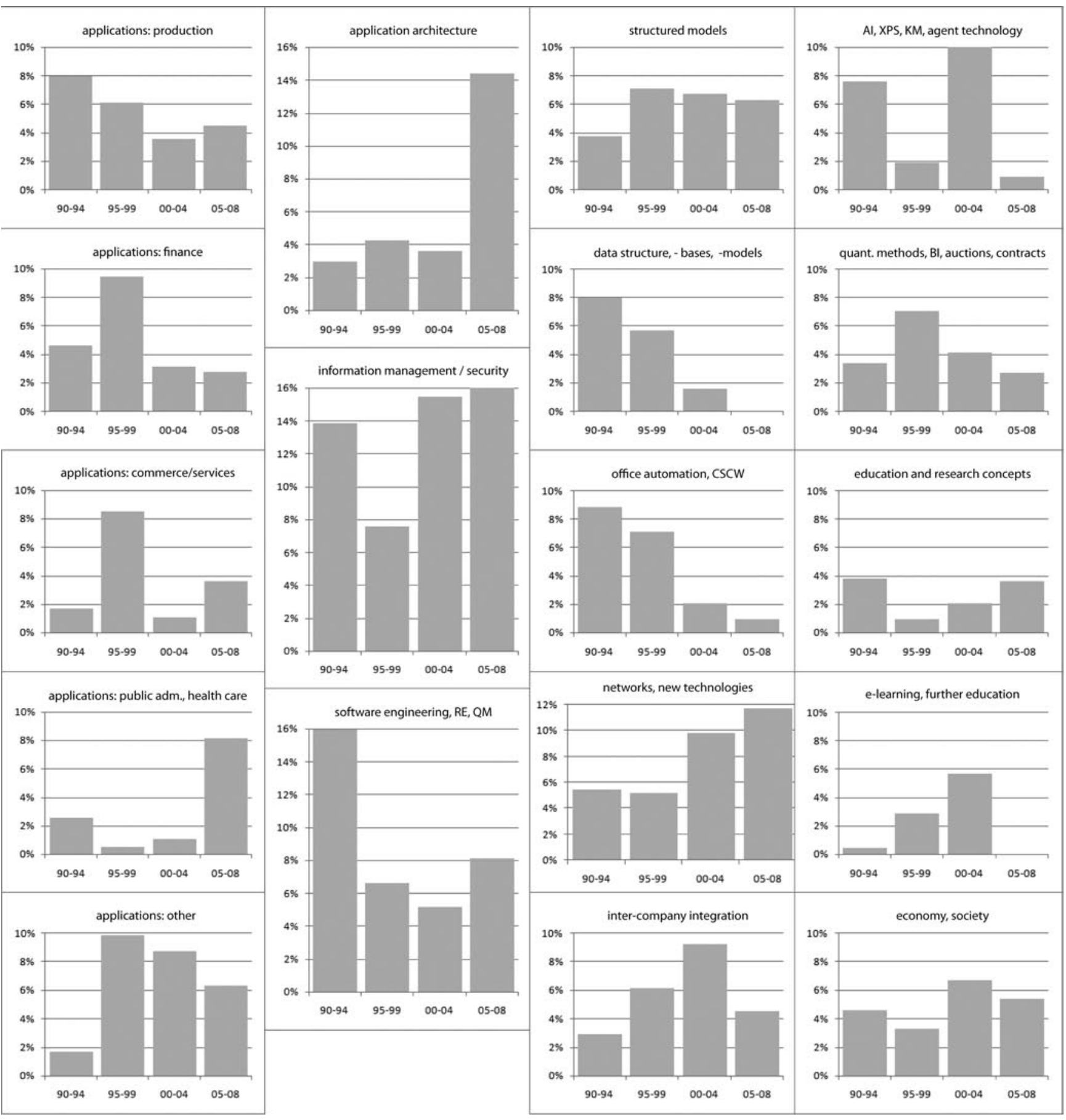

Fig. 4 Development of article content in five-year intervals

\section{In 1976}

a) trend towards corporate decentralization caused by modern data processing,

b) HIPO - a design and documentation technique.

Topic a) belongs to the long term subject "distributed processing" that had already started in ed, topic b) initiated a series of articles on a variety of methods and techniques for systems/program development, among which are decision tables that had already been addressed before in the journal in 1971. The topic seems logical considering the fact that in the 1970s at least larger companies preferred individual programming instead of obtaining standard software.

In 1977

a) the design of the data basis in dispositive systems,

b) a paper on method banks.

Topic a) is the first of several articles on the design of databases (among them also some on the entity-relationship model), topic b) initiated the discussion on method banks that proved to be less successful in the end.

In 1979

a) dialog design in DIABAS,

b) on the realization of integrated office information systems.

Topic a) is the beginning of a series of papers on user friendly program design, topic b) on office automation, first with 


\begin{tabular}{|c|c|}
\hline Issue & Special focus \\
\hline $1 \mid 1990$ & Business and information systems engineering position at the beginning of the $90 \mathrm{~s}$ \\
\hline $2 \mid 1990$ & Structure and tasks of information systems management \\
\hline $3 \mid 1990$ & Object oriented application systems and systems software for the $90 \mathrm{~s}$ \\
\hline $5 \mid 1990$ & Application architecture - a basis for system independent solutions? \\
\hline $6 \mid 1990$ & Computer aided management workplaces \\
\hline 1|1991 & CASE - the way is the goal \\
\hline $3 \mid 1991$ & Hypertext - from scroll to information mosaic \\
\hline $4 \mid 1991$ & Enterprise-wide data modeling - problems and approaches \\
\hline $5 \mid 1991$ & Applications of neuronal networks \\
\hline $2 \mid 1992$ & Reengineering - new concepts using old ingredients \\
\hline $4 \mid 1992$ & Security of application systems \\
\hline $6 \mid 1992$ & Local government - with technical innovations to administrative innovations \\
\hline $2 \mid 1993$ & Computer support for cooperative work \\
\hline $4 \mid 1993$ & Migration - and no end \\
\hline $5 \mid 1993$ & SAP-introduction \\
\hline $1 \mid 1994$ & Information processing in financial services companies \\
\hline $4 \mid 1994$ & Information systems in health care \\
\hline $1 \mid 1995$ & Results of empirical research \\
\hline $5 \mid 1995$ & Business process modeling \\
\hline $3 \mid 1996$ & Information systems in finance \\
\hline $3 \mid 1996$ & New forms of organization and their support by IT \\
\hline $4 \mid 1996$ & Applications of Petri-nets \\
\hline $1 \mid 1997$ & The year-2000-problem and other aspects of temporal information systems \\
\hline $2 \mid 1997$ & IT in logistics: efficient coordination of the transport chain \\
\hline $3 \mid 1997$ & Nets and electronic markets \\
\hline $6 \mid 1997$ & Computer assisted learning \\
\hline $1 \mid 1998$ & Electronic selling \\
\hline $3 \mid 1998$ & Telework and telecooperation \\
\hline $6 \mid 1998$ & Management support systems \\
\hline $1 \mid 1999$ & Application systems made from components \\
\hline $2 \mid 1999$ & Information systems in finance \\
\hline $4 \mid 1999$ & Networked small and medium sized enterprises \\
\hline $5 \mid 1999$ & External data in management support systems \\
\hline $2 \mid 2000$ & Information processing for management \\
\hline $6 \mid 2000$ & Security in communication and information technology \\
\hline $1 \mid 2001$ & Virtual education and further education \\
\hline $2 \mid 2001$ & Agent technology - cooperating software agents in business use \\
\hline $5 \mid 2001$ & Knowledge management in consulting \\
\hline $6 \mid 2001$ & Electronic marketplaces and supply chain management \\
\hline $3 \mid 2002$ & Software development for web-based application systems \\
\hline $5 \mid 2002$ & Coupling of application systems \\
\hline $2 \mid 2003$ & Outsourcing of information processing - current developments, new results \\
\hline $3 \mid 2003$ & Peer-to-peer - technologies, architectures, and applications \\
\hline $5 \mid 2003$ & Business \& information systems engineering and economic theory \\
\hline $1 \mid 2004$ & $\begin{array}{l}\text { Data warehousing and data mining - applications, } \\
\text { technologies, practical experiences }\end{array}$ \\
\hline
\end{tabular}

microcomputers, then with personal computers.

In 1981

a) standard application software for cost and results accounting,

b) a structure of modules for application software systems.

Both papers mark the beginning of a number of articles on corporate standard software.

In 1983

a) electronic mailbox systems,

b) metrics of software quality,

c) the prototypical expert system of Nixdorf.

By means of a), several papers start dealing with office communication using modern communication technology, by b) articles with software quality, and by c) articles with the temporarily hype (and meanwhile less visible) subject expert systems. In 1985

a) general principles of software engineering,

b) phase specific principles of software engineering,

c) tool integration in software development methodologies.

All three subjects address a systematic approach to systems development which was, as mentioned before, partly covered in previous years by the description of individual methods.

In 1987

- With the topic "development of personal computer application in branded goods companies" articles deal with the application of PCs in corporate functional areas for the first time, which was repeatedly taken on later.

In 1989

a) analysis and design of planning systems in software houses,

b) objects of corporate planning in software houses.

Both papers mark the beginning of a systematic discussion of the impact and importance of software houses that had been addressed only in single cases (e. g. on the occasion of mbp's 25th anniversary).

Supplemental issues like those of ed or issues with a special focus such as in WIRTSCHAFTSINFORMATIK did not exist with AI. Issue 2/1982 was devoted to mbp's 25th anniversary and a forecast for the future development of electronic data processing and applied computer science. Worth mentioning are primarily the 
articles by famous pioneers of computer science and BISE.

- Konrad Zuse: What was the basis 25 years ago?

- Heinz Nixdorf: From hardware to software - a change in importance, and

- Erwin Grochla: Corporate consequences of the development of information technology.

In his paper "From electronic data processing to Angewandte Informatik: 25 years of cooperation between mbp and Vieweg" the executive manager of the publishing house Vieweg once again points to the strong ties between mbp and the journal (Lube 1982).

In spite of the multitude of topics contained in AI one may miss, from the perspective of BISE, a more thorough discussion of corporate application systems in specific industries like production, retail trade, or financial services, or in typical functional areas like purchasing, production, or sales and distribution. This argument can be returned by the aspect that AI - as its name suggests, and different from its successor WIRTSCHAFTSINFORMATIK - intended to be a forum for all application areas of computer science and not for BISE alone.

\section{WIRTSCHAFTSINFORMATIK}

\subsection{Organization and structure}

The BISE community defines its field not as one of many computer science application areas but rather as a distinct scientific branch, between management and business administration on the one hand and computer science on the other hand (Mertens et al. 2002). Academia in Germany is organized in two associations: WKWI ("Wissenschaftliche Kommission Wirtschaftsinformatik im Verband der Hochschullehrer für Betriebswirtschaft e. V.") is open for professors from traditional universities, AKWI ("Arbeitskreis Wirtschaftsinformatik") is the organization of professors from universities of applied sciences. GI ("Gesellschaft für Informatik e. V.") is the general computer science association for professionals from research and business practice. GI set up a department for BISE (formerly called Department 5), which is open to anybody interested.

Most of the professors have a management and business administration back-

\begin{tabular}{|ll}
\hline Talo. 3 & Special focus issues and special issues of WIRTSCHAFTSINFO RMATIK \\
\hline Issue & Special focus \\
\hline $3 \mid 2004$ & IT-controlling \\
\hline $5 \mid 2004$ & Reference modeling - current methods and models \\
\hline $1 \mid 2005$ & Mobile systems and applications - hammer looking for nails \\
\hline $3 \mid 2005$ & IT in health care - information systems for tomorrow's health care \\
\hline $5 \mid 2005$ & Electronic government \\
\hline $1 \mid 2006$ & Internet economy \\
\hline $3 \mid 2006$ & Interoperability and IT integration \\
\hline $5 \mid 2006$ & IT/business alignment \\
\hline $1 \mid 2007$ & Personalization and informational self-determination - an insolvable contradiction? \\
\hline $3 \mid 2007$ & Industrialization of software development - state of the art \\
\hline $5 \mid 2007$ & Changes in energy industry - challenges for IT \\
\hline $1 \mid 2008$ & Service-oriented architectures and web services \\
\hline $3 \mid 2008$ & Integration of production and service- hybrid value creation \\
\hline $5 \mid 2008$ & IT-compliance and IT-governance \\
\hline Year & Special issue \\
\hline 2000 & IT and personnel \\
\hline 2007 & Location of software under the influence of industrialization and globalization \\
\hline
\end{tabular}

ground. They held their ground against other scientific disciplines, especially against computer science. The demarcation of the disciplines was explicitly communicated in a letter of WKWI addressed to all economics and business departments requesting not to consider scientists from other disciplines for positions in BISE (n. a. 1991). Nevertheless, there are strong ties to computer science and other sciences, and the secession of BISE from GI, which was proposed by some, fortunately did not happen.

Against the background of the relatively new discipline finding itself one has to consider the initiation of the WIRTSCHAFTSINFORMATIK journal in 1990. The community predominantly agreed on the necessity of establishing a strong common journal in order to strengthen and consolidate the discipline.

The editors and publishers of the journal Angewandte Informatik thought that, caused by the ever growing importance of computer science and its application domains as well as by the increasing number of domain specific academic institutions, it was time to specialize and consolidate. Therefore it was logical for the journal to offer the community to focus on BISE in the future and to fulfill the desired function of a central publication channel. After successful negotiations with the steering committees of WKWI and the Department 5 of GI, conforming resolutions of the assemblies, and approval by the GI-presidency a positive decision was made. The speakers of both associations are members of the editorial board ex officio.

Starting with volume 32, 1990, the journal has been published under the name WIRTSCHAFTSINFORMATIK. "It wants to be understood as the central publication channel of the fast growing and networkbuilding German speaking community of researchers and business practitioners in the field of business and information systems engineering [...]. Together, they face the tasks of developing the theoretical foundations of activities (with the goal to achieve persistent procedural methods in spite of vehement technological development) and of an appropriate technology transfer (with the goal to make better solutions available for practice more rapidly and to control the cost of systems development and applications" (n. a. 2008c). The first issue $1 / 1990$ is focused on clarifying the position of the discipline.

The journal is published bi-monthly. Each volume comprises between 472 and 728 pages. Besides the specific content focus the changes in comparison with the predecessor Angewandte Informatik include the following:

- The editorial board was extended to about 25 persons from academia and business practice.

- The members of the editorial board represent the most important universities 


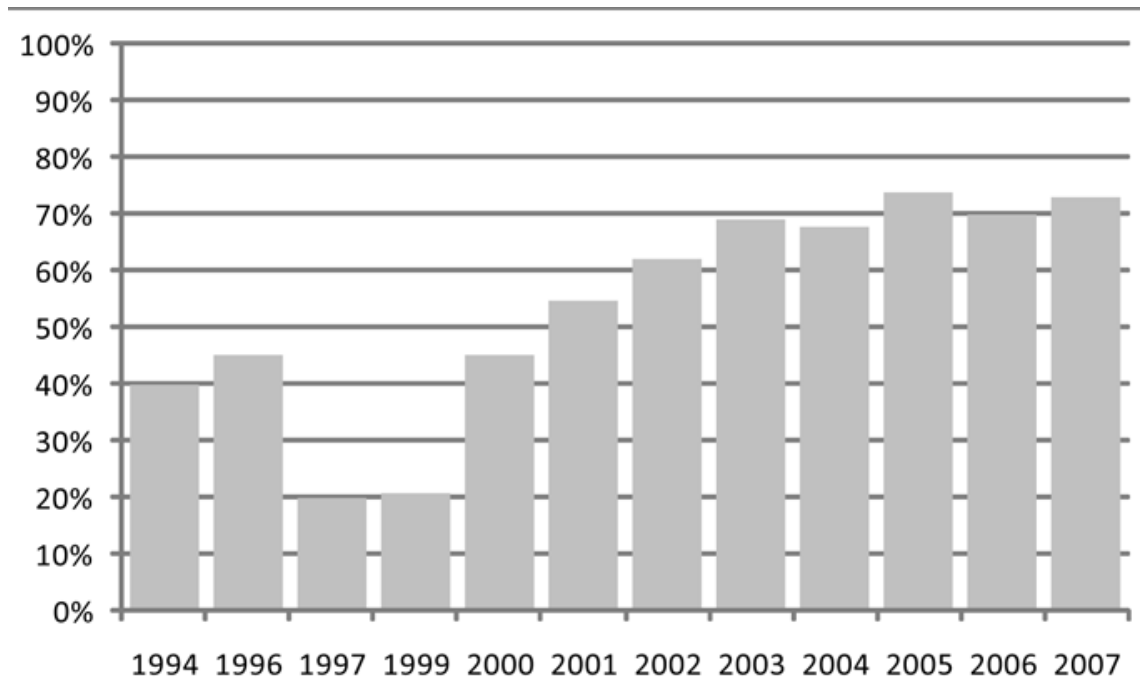

Fig. 5 Development of the rejection quota

that have a focus on business and information systems engineering, universities of applied sciences, management and business administration research, computer science, IT users, manufacturers and consultants, WKWI, GI, and - since 2004 - universities from other European countries.

- The editors serve for a limited term. The editorial board elects new members on a rolling basis.

- The editor-in-chief is appointed by the publisher, on proposal by the editorial board, and serves for a limited term.

- Individual members of the editorial board are responsible for certain departments.

- The editorial board convenes regularly, in the beginning twice a year, yearly since 1995.

Since 1990, a number of 91 persons have been listed as members of the editorial board, among them 67 professors from 59 universities and 24 practitioners. Researchers from foreign-language-countries are associated editors.

The following persons have been editors-in-chief:

- from 1990 to 1991: Prof. Dr. Paul Schmitz, Köln,

- from 1990 to 1991: Prof. Dr. Dr. h. c. Norbert Szyperski, Köln,

- from 1990 to 2000: Prof. Dr. Dr. h. c. mult. Peter Mertens, Nürnberg,

- from 1992 to 2000: Prof. Dr. Ulrich Hasenkamp, Marburg,

- from 1998 to 2008: Prof. Dr. Wolfgang König, Frankfurt (Main),

- since 2006: Prof. Dr. Hans Ulrich Buhl, Augsburg.
Schmitz, together with the business administration oriented scientist Szyperski, had significant influence on the development of the journal Angewandte Informatik as outlined in section 2 and on narrowing the focus towards BISE, which eventually led to the journal's conversion to WIRTSCHAFTSINFORMATIK.

Transferring the chief position to Mertens in 1992 strengthened the broad acceptance and embedding in the community, particularly because Mertens besides engaging in numerous professional committees - built a bridge to computer science. In respect to content, his influence was a strong commitment to practice, especially regarding the increasing application of standard software for business applications. Under his aegis, the number of readers from business practice increased. This was also instrumental for improving the standing of the BISE discipline as such. By introducing double-blind review procedures for the articles ${ }^{4}$, the basis for rankings according to international standards was prepared.

The improvement of the journal's standing - also in respect to the growing importance of rankings - was König's guideline during his period as editor-in-chief. The successful efforts corresponded to intensive discussions on rigor vs. relevance in BISE research (e. g. Winter et al. 2007). At the same time, the international position of the journal and of the BISE discipline gained further importance.

4 Until 1997 the reviewers were anonymous to the authors, but the reviewers knew the names of the authors
Buhl, in his so far short time as editorin-chief, has achieved the breakthrough to going international in conjunction with several members of the editorial board and the publisher. Starting with the 51st volume 2009, the journal will appear in a German version (print and online) - under the name WIRTSCHAFTSINFORMATIK as before - and additionally in English (online) under the name "Business \& Information Systems Engineering. The International Journal of WIRTSCHAFTSINFORMATIK". The introduction of a third line of publication especially for business practitioners will allow the other two lines to concentrate on a high scientific level, which should further improve the international ranking position. Besides the economic investment by the publishers, the funding of the project by several practice partners is worth mentioning.

With the transformation from Angewandte Informatik to WIRTSCHAFTSINFORMATIK, several sections have been installed for which individual members of the editorial board were responsible. Tab. 2 lists the sections and the persons in charge, who have changed in some cases in the course of the years.

In 1995, the website http://www. wirtschaftsinformatik.de was set up. In 2001 and 2008, it has undergone major re-launches. Subscribers, members of the Wirtschaftsinformatik department of GI, and users of participating libraries have full access to the archive (with full texts from volume 1995 on) at no extra cost. Usage analyses show that the website is of growing importance in addition to the classical print version of the journal. Currently there are plans to extend the website beyond the journal in order to establish a portal for the field of BISE.

\subsection{Scientific articles}

The part of the journal containing articles is organized such that half of the issues are devoted to a special focus. Often, other sections of focus issues also provide content relevant to the focal subject. Issues that do not have a special focus mainly contain recent research papers.

The paper by Szyperski, Mertens, and König (in this issue) elaborates on content highlights and developments of WIRTSCHAFTSINFORMATIK. Therefore, in this paper, only an overview is presented. Issue 4/2004 contains a scient- 
ometric analysis of the journal (Resch and Schlögl 2004).

Fig. 4 shows the development of content in the course of time (five year intervals ${ }^{5}$ ). The categories were deduced from a matrix that was developed early in the 1990 s in order to match competence fields and members of the editorial board.

The overview shows a continuing focus on information management. In the first interval, software engineering was strong, in the last application architecture is dominating. Continuous decrease can be seen with data structure/ data bases/ data models and office automation/ computer supported cooperative work (CSCW). In contrast, an increase occurred in the case of new technologies. Some temporary clusters of certain subjects can be explained by focus issues of the journal and by external effects like science foundation research programs. A general observation is that especially the focus issues of the journal reflect the development of the discipline business and information systems engineering. The focus of issue 1/1990, "Business and information systems engineering - definition of the position at the beginning of the 90 s", deserves special attention because it pointed out important aspects of the development and the current state of the discipline. Tab. 3 lists all special focus issues of volumes 1990 through 2008 in chronological order and the special issues.

An opinion poll in 1998 showed that the readers (researchers, business practitioners, and students) were satisfied with most of the content to a good or medium level. Researchers wanted more publications regarding educational and research concepts, students more on data structures, databases, and data models, and practitioners were not quite satisfied with the coverage of security and privacy (in Fig. 4 contained in information management). The articles that are part of a special focus are ranked best. All categories of readers gave high ratings for "state of the art" and "catchword" papers, just as for book reviews, comparative literature studies and the journal website. A second poll in 2001 emphasized the reader interest in application systems, information management, and application integration.

In the case of journal rankings (n. a. 2008b) the proportion of rejected submissions plays an increasingly important role.

\footnotetext{
5 "The last interval comprises only four years".
}

Fig. 5 gives an overview based on available data. A complete time series is not available.

\section{Outlook}

Since the first chairs had been established around 1970, BISE has become a major discipline at almost every university. The importance is emphasized further by the success of the large annual conferences for BISE (alternating WI and MKWI) ${ }^{6}$. The international visibility of researchers from German-speaking countries is limited because most of them still publish in German. The inauguration of "Business \& Information Systems Engineering. The International Journal of WIRTSCHAFTSINFORMATIK" as a version identical to WIRTSCHAFTSINFORMATIK as regards content may help to draw more international attention to research from German-speaking countries.

In recent years, the website turned out to be indispensable. The German-language version of the journal will continously be available in print and online. The English-language version BISE is a pure online journal with good international visibility and availability via SpringerLink. The journal's website will be enhanced to become a protal for everybody interested in the field of business and information systems engineering, beyond the journal.

In addition, the orientation towards business practice will be strengthened by the publication of a neighboring journal with the title "WIRTSCHAFTSINFORMATIK \& Management" (in German, in cooperation with the journal "HMD Praxis der Wirtschaftsinformatik"). This step will allow to better position the (scientific) journal WIRTSCHAFTSINFORMATIK and its English-language counterpart in view of the international ranking criteria.

\section{References}

Lube F (1982) Von der "elektronischen datenverarbeitung" zur "Angewandten Informatik" 25 Jahre Zusammenarbeit mbp - Vieweg. Angewandte Informatik 24(2):XIII-XVI

Mertens P et al (eds) (2002) Studien- und For6 The next conference "Wirtschaftsinformatik"
(WI) will take place in Vienna in Feb. 2009, the
next "Multikonferenz Wirtschschaftsinformatik"
(MKWI) in Göttingen in Feb. 2010.

\section{Abstract \\ Ulrich Hasenkamp, Peter Stahlknecht \\ Wirtschaftsinformatik - Evolution of the Discipline as Reflected by Its Journal}

In 1959, the journal "elektronische datenverarbeitung" (electronic data processing) was founded. Later it was renamed as "Angewandte Informatik" (applied computer science). Due to the diversification of computer science and the emergence of the discipline "business and information systems engineering" (BISE) the journal was focused on this discipline. Accordingly, the name was changed to WIRTSCHAFTSINFORMATIK (the German word for BISE). Fifty volumes of the journal reflect major developments and varying topics of the discipline. By installing a broad editorial board comprised of researchers and practitioners as well as by cooperation with the major scientific associations the journal became the central publication in the field. The paper gives a survey of organization, design, thematic focuses, and important subjects. Thus, by browsing through the contents of the journal the development of the scientific discipline Wirtschaftsinformatik is illustrated.

Keywords: Wirtschaftsinformatik, Electronic data processing, Applied computer science, Scientific discipline, Journal, Business and information systems engineering 
schungsführer Wirtschaftsinformatik, 3. edn. Vieweg, Wiesbaden, p 13

na (1991) Empfehlungen an die WISO-Fakultäten für Berufungen in Wirtschaftsinformatik. Schreiben der Wissenschaftlichen Kommission Wirtschaftsinformatik im Verband der Hochschullehrer für Betriebswirtschaft e. V., Saarbrücken, Oct. 1991

na (2008a) Arbeitskreis Wirtschaftsinformatik an Fachhochschulen (AKWI). http://www.akwi.de. Accessed 2008-08-03

na (2008b) WI-Orientierungslisten - WI-Journalliste 2008 sowie WI-Liste der Konferenzen, Proceedings und Lecture Notes 2008. WIRTSCHAFTSINFORMATIK 50(2):155-163 na (2008c) WIRTSCHAFTSINFORMATIK - Profil. http://www.wirtschaftsinformatik.de/index. php;do=zs_pr/site=wi/sid=54ea96964402306 07f1149ed01840507. Accessed 2008-08-03 na (2008d) Wissenschaftliche Kommission WI Wirtschaftsinformatik. http://pbwi2www.unipaderborn.de/WWW/VHB/VHB-Online.nsf/ID/ DE_WK_WI_Start. Accessed 2008-08-03

Resch A, Schlögl C (2004) Die Wirtschaftsinformatik aus der Sicht ihres Hauptpublikationsorgans. Eine szientometrische Analyse der Zeitschrift Wirtschaftsinformatik / Angewandte Informatik. WIRTSCHAFTSINFORMATIK 46(4):302-310

Winter R, Baskerville R, Frank U, Heinzl A, Hevner $A R$, Venable JR (2007) Relevance and rigour what are acceptable standards and how are they influenced? WIRTSCHAFTSINFORMATIK 49(5):403-409

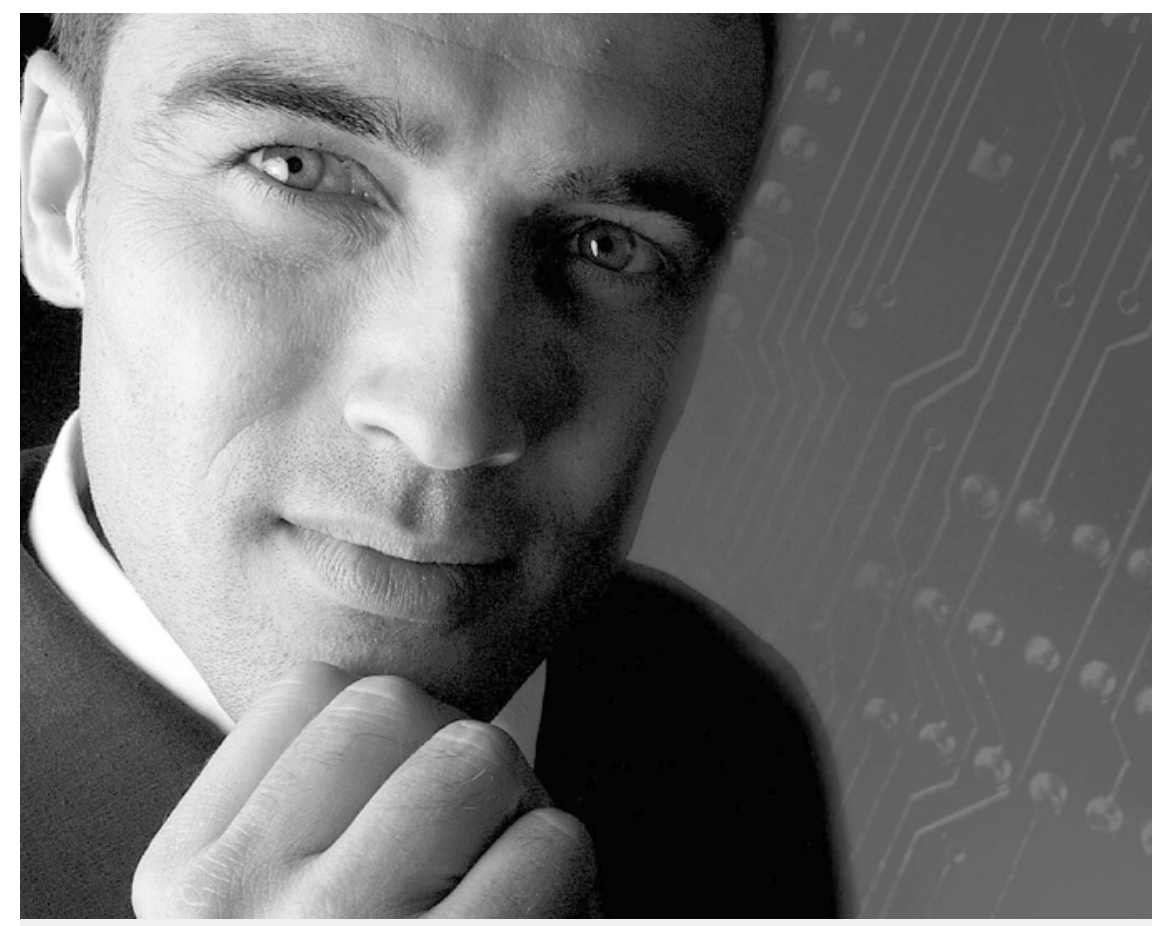

\section{We proudly present}

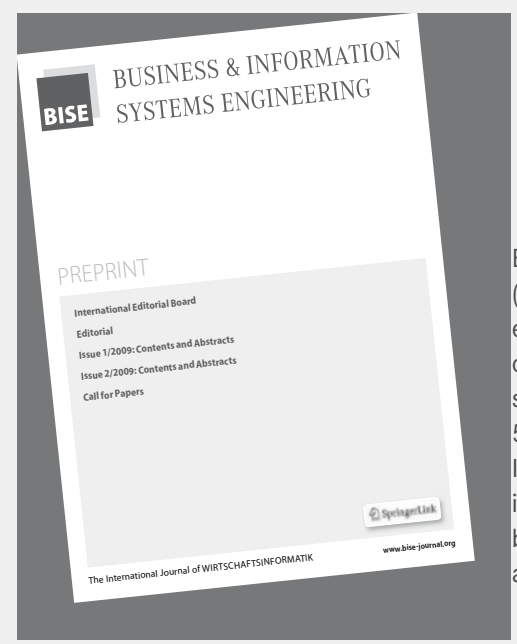

Business \& Information Systems Engineering (BISE) is the new peer-reviewed scholarly e-journal for the entire techno-economically oriented community with a focus on design science-oriented research. It continues the 50 years" tradition of the journal WIRTSCHAFTSINFORMATIK by that all articles appear both in English and in German. Moreover, authors benefit from our double-blind, constructive, and rapid review process.

"I believe the time is opportune for the IS community to provide such outlets for design researchers. BISE, however, has some unique advantages for positioning itself as a desirable outlet for design science research. “

Alan R. Hevner

\section{www.bise-journal.org}

